\title{
Images in paediatrics
}

\section{The first images of varicella lesions in the bladder}

A 3-year-old boy with a recurrent prolapsing vesicostomy presented with multiple lesions over his prolapsed bladder mucosa figure 1 . He had recently contracted varicella, and had developed characteristic 'chickenpox' lesions over his torso. The lesions on his bladder were of similar appearance and it was felt that the varicella was the likely cause as the virus can sometimes affect mucosal membranes. The bladder lesions resolved over the same course of time as those elsewhere.

Primary infection with the varicella zoster virus, is characterised by a rash, often accompanied by fever and malaise, which starts as macules, then progresses rapidly through papular and vesicular stages, before crusting over. Skin manifestations are the most common, but it can also affect the mucosa

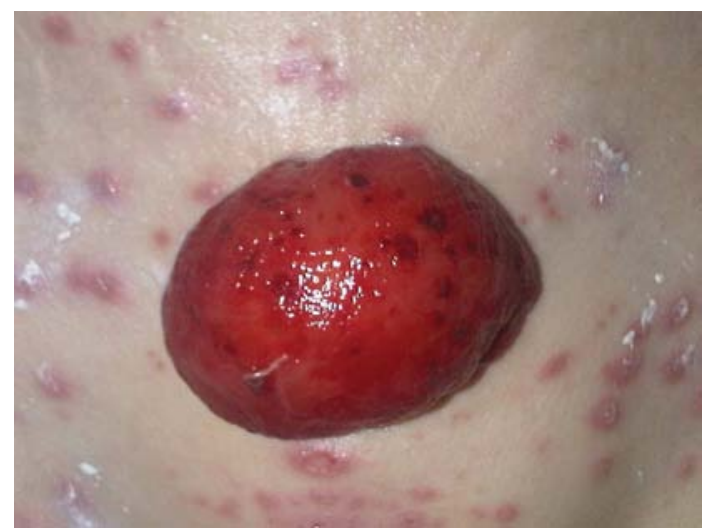

Figure 1 Prolapsed vesicostomy with varicella lesions of bladder mucosa. Note similar lesions affecting skin of abdominal wall. of the conjunctivae, oropharynx and introitus of the genitourinary tract. 1

Varicella affecting bladder mucosa, is rarely reported. A single case report describes a child with varicella affecting skin and oral mucosa who developed haematuria. ${ }^{2}$ At cystoscopy, he was found to have haemorrhagic lesions in his bladder. In our patient, it was possible to directly visualise the bladder mucosa, which was not actively bleeding. It is possible that bladder mucosa is more commonly affected than is documented, as in the absence of macroscopic haematuria, it is unlikely that it would come to the attention of clinicians. Although haematuria should be investigated, it may be useful to consider the possibility of bladder lesions in children with varicella who present with this symptom.

\section{Charlotte Marie Holbrook, Simon Waller}

Department of Paediatric Nephrourology, Evelina Children's Hospital, London, UK

Correspondence to Dr Charlotte Marie Holbrook, Evelina Children's Hospital, Department of Paediatric Nephrourology, St Thomas' Hospital, Westminster Bridge Road, London, SE1 7EH, UK; cmholbrook99@hotmail.com

Contributors SW identified the patient, obtained the image and consent from the guardians of the patient. $\mathrm{CH}$ wrote and drafted the manuscript and undertook the literature review. The draft was revised by SW.

Competing interests None.

Patient consent Obtained.

Provenance and peer review Not commissioned; externally peer reviewed.

Received 8 February 2012

Accepted 22 February 2012

Published Online First 7 May 2012

Arch Dis Child 2012;97:732. doi:10.1136/archdischild-2012-301789

\section{REFERENCES}

1. Heininger U, Seward JF. Varicella. Lancet 2006;368:1365-76.

2. Amar AD. Hematuria caused by varicella lesions in the bladder. JAMA 1966;196:450. 